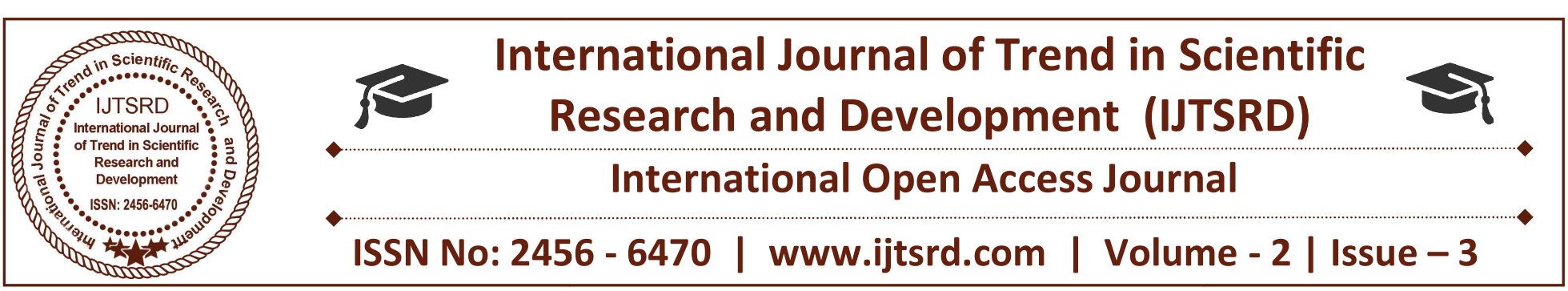

\title{
Industrial Management: A Strategic Threat for Companies
}

\author{
Poonam \\ Lecturer, Department of Humanities, Babu Banarsi Das National Institute \\ of Technology and Management, Lucknow, Uttar Pradesh, India
}

\section{INTRODUCTION}

Industrial management studies the basic concept of management and all other management related aspect, which are considered essential for companies. The knowledge of industrial management is important to develop an understanding of various functions of management, role of workers and engineers, production and operations functions, quality management, organizational behavior, industrial relations etc. Proper knowledge in industrial management would mean a successful career. Management inputs strengthen the decision-making powers of employees in organizations; they help in understanding the techniques of resource optimization to achieve business results. In today's complex business environment, every employee in his workplace needs to plan, organize, direct coordinate and control. Not only this, proper knowledge of industrial management is required to save our environment then only problems regarding quality, customer satisfaction, productivity, profitability etc. would solve.

Keywords: Industrial management, production, productivity, Inventory control, EOQ, SCM, Quality control, Environmental issues

\section{INTRODUCTION}

Industrial management is the combination of two words- industrial and management. Industrial implies referring to industry. Industry may be defined as "the application of complex and sophisticated methods to the production of economic goods and services."The complex and sophisticated methods refer to the use of machines which improve the quantity and quality of production. "Management is a process used to accomplish organizational goals."

Industrial management is the branch of engineering that deals with the creation and management of systems that integrate people and materials and energy in productive ways.

Industrial management is the organizational process that includes strategic planning, setting objectives, managing / resources, deploying the human and financial assets needed to achieve objectives, and measuring results. It also includes recording and storing facts and information for later use or for others within the organization.

Industrial management, as a field of business administration, studies the structure and organization of industrial companies. It comprises those fields of business administration that are necessary for the success of companies within the manufacturing sector and the encompassing services (primarily operations management, marketing, and financial management).

\section{Development of industrial management:}

Industrial revolution-the rise of factories

- Machine power began to substitute for human power

- It led to mass production of economical goods

- Improved and less costly transportation systems became available which created larger market for goods

- Larger organizations developed to serve larger markets 
Scientific management: The first effort in the direction of improved efficiency was made by Frederick W. Taylor.

- Use of scientific method to define "one best way for a job to be done.

- Increased efficiency by selecting the right people for the job and training them to do it in one best way.

- Motivation to workers due to incentive wage plans.

- Separation of managerial work from operative work.

Gilbreths developed "time and motion" studies.

Henry Ford introduced the division of labour in the factories.

Human relations movement- Importance of human relations was made by the Hawthorne studies from 1927 to 1932 . The research was supervised by Elton Mayo. He emphasized on workers efficiency depended on a wide range of relations within groups as well as on compensation.

Modern trends- modern technological / devices, particularly in the areas of computer, electronics, thermodynamics and mechanics, have made automatic and semi-automatic machines a reality. The development of such automation is bringing about a second industrial revolution and is causing vast changes in commerce as well as the way work is organized.

Research Objective: The main objective of industrial management is to produce the right quantity of right quality goods at the right time. These are attained through:

- Unit cost of the product should be estimated carefully and every effort should be made to stick to the cost standards.

- Selection and acquisition of machinery and equipment according to production process.

- The per unit materials costs should be specified and efforts should be made to increase the inventory turnover of all types of inventories- raw materials, work-in-progress and finished goods.

- Manpower should be skilled, knowledgeable and motivated.

- Manufacturing a qualitative product on schedule, at the lowest possible costs, with maximum asset turnover, to achieve consumer satisfaction.
- Manufacturing schedule should be proper because it directly affects the cost, quality and the goodwill of the business.

- Equip employees to learn and apply various managerial tools and techniques for improved decision-making.

- Industrial management focuses on environment and environmental hazards, encompassing pollution control concepts, waste management strategies, environment management issues and organizational responsibilities towards environment.

- Increasing productivity and profitability of the organization with customer satisfaction.

\section{Applications of Industrial Management}

- Design and development

- Plant layout and material handling

- Method study and work measurement

- Production forecasting

- Production planning and scheduling

- Proper inventory control

- Quality control

- Production control

- iethod analysis

- Motivate workers

\section{Problems of Industrial Management}

The industrial management is very difficult because of changes in market, technology, attitude of people, government regulations, etc. The regular problems faced in industrial management are:

- Problem of selection of plant location.

- Problem of selection of best production method as per the requirement, sources available and quality of the method.

- Problem of suitable selection of plant layout for production of quality products and services and minimizes the breakdown in the production process.

- Problem of designing of product.

- Problem of production and inventory control.

- Problem of quality control which can be reduced by installing inspection activities at various level of production.

- Labour problems can be minimized by work measurement, work analysis, work supervision, and motivational method of wage payment etc.

- Problem of cost control can be minimized by reducing the wastage at all level and by maintaining economy in production. 


\section{Production and Productivity}

Production is defined as the conversion of inputs into output. Inputs may be in the form of materials, labour, capital, energy, information etc. Output can be in the form of a product, service or information.

Productivity is defined as the ratio of output to input of a production system.

Productivity= Output/Input

\section{Techniques of increasing productivity}

- Product development

- Specialization and standardization

- Market, consumer and product research

- Value analysis

- Process planning and research

- Method study

- Work measurement

- Employee training

- Production planning and control

- Material control

- Plant maintenance

- Improved working conditions

- Safety

- Personnel Policy

- Incentives

\section{Benefits of increasing productivity}

- To earn good profit because of reduction in costs.

- To have better utilization of resources.

- To stand better in the market.

- Higher wages

- Better working conditions and improved morale.

- Job security and satisfaction.

- Better quality goods at reduced prices which helps to raise their standard of living.

- Higher profits earned by factories will bring more revenue to the government by taxation.

- It helps to increase the welfare of the nation and development of national economy.

- It increases per capita income.

- Development of the nation.

By properly applying these techniques of increasing productivity, profitability of an industry would definitely increase along with this reputation of an industry would also increase.

\section{Management Functions}

Industrial management requires basic understanding of the principles of management because it helps in achieving the goals of an organization and individual employee. Without management functions the concept of industrial management is not possible. Management functions are:

- Planning-Planning is the fundamental function of management. It is a rational approach to the future. "'Planning is basically deciding the future course of action". It plays a very important role in rational decision-making.

- Organizing- It is the effective designing of the work pattern and managers need to understand organizations systems and structures, delegation of authority, span of control, etc.

Staffing- It is necessary to man or staff the positions, so that work runs smoothly. Staffing is the process by which managers select, train, promote and retire their subordinates.

- Directing- It is the process by which the actual performance of employees is guided towards common goals of the enterprise. It involves leadership, communication, motivation and supervision.

- Controlling- It is a comparison between the actual performance and the set standards.

\section{Importance of Management Functions}

- Management provides guidance and controlling to various activities of an organization.

- Management coordinates activities of different departments in an organization and creates teamspirit in different persons.

- Management provides new ideas and vision to the organization.

- Management tackles business problems and provides a tool for the best way of doing job.

- Management provides stability to the organization.

- Management helps in grooming the personality of employees thereby increasing efficiency, productivity and profitability

In industrial management, management functions play very important role in achieving the organizational goals as well as individual employees. While discussing management functions there is also very important issue regarding material management which needs to be discussed to get the quality product on time. The scope of material management varies greatly from company to company and may include 
materials planning and control, production planning, purchasing, inventory control and stores, in-plant materials management and waste management. Main issues are:

- Manufacturing and process of value addition.

- Operation, keeping pace with the requirements of environment and competition.

- Delivery lead time and manufacturing strategies.

- Supply chain management.

- Manufacturing process.

\section{Inventory Control}

In industrial management, inventory control is very important. It is the process by which materials of correct quality and correct quantity are made available as and when required. It is a technique of maintaining the size of the inventory at some desired level keeping in mind the best economic interests of the production system. The desired level can neither be too high nor too low because high level of inventory will lead to increase in carrying cost while low level will lead to increase in ordering cost. Inventories should be stored at various levels like minimum inventory level, maximum inventory level, re-order level, average inventory level and danger inventory level. Various techniques of inventory control are as follows:

- $\mathrm{ABC}$ analysis

- VED analysis

- HML analysis

- SDE analysis

- SOS analysis

- FSN analysis

- XYZ analysis

\section{Importance of Inventory Control}

- Avoiding lost sales

- Gaining quantity discounts

- Reducing ordering costs

- Achieving efficient production runs

- Reducing risk of production shortages

- Optimum investment and efficient use of capital

- Availability of materials

- To check wastage

- For the success of business

Along with the inventory control, the concept of supply chain management is also very important. Industry can be managed by managing supply chain properly. It helps in getting the right quantity and quality of products and services at right time and at right place. In industrial management, the concept of supply chain management is also very important. If the company wants to satisfy its consumers so supply chain should be properly managed.

\section{Supply Chain Management}

A supply chain is a network of supplier, manufacturing, assembly, distribution and logistics facilities that perform the functions of procurement of materials, transformation of these materials into intermediate and finished products, and the distribution of these products to customer. The objective of the supply chain should be to maximize overall supply chain profitability. Successful supply chains manage flows of product, information, and funds to provide a high level of product availability to the customer while keeping costs low. The performance of supply chain can directly create an impact on the productivity and profitability of the company. Supply chain management involves some important decisions:

- Where-to-make and what-to-make or buy decisions.

- Creation of communication channels for critical information and operational improvements with suppliers, distributors and customers.

- Inventory decisions include quantity, quality and location of inventory.

- Demand planning and forecasting.

- Inbound operations including transportation from suppliers and receiving inventory.

- Outbound operations including transportation to customers.

- Order promising, accounting for all constraints in the supply chain.

With the help of supply chain management, consumer would get products or services on just-in-time by removing various types of waste as waste of overproduction, waste of waiting, waste of transportation, waste of stocks, waste of motion and waste of making defective products.

\section{TQM (Total Quality Management)}

TQM is and effective system for integrating the quality maintenance, quality development and quality improvement efforts of different functions of business to enable production and service at most economical levels to meet customers satisfaction. It focuses on various issues like universal responsibility for quality, consumer satisfaction means try to find out consumers needs, wants and desires and make products or services available to consumers on time at reasonable price, prevention of defective products or services and 
last includes continuous improvement of an organization like proper plant location, plant layout, machines, proper training and development programs for employees, incentives, performance appraisal, proper supply chain management, proper production planning and control etc. Without TQM, industrial management is just impossible.

\section{Environmental Issues}

Environment means encircle on surrounding. Environment includes both biotic and abiotic factors that have some impact on growth and development of certain organism. Ecological balance is maintained by the combination of these factors. But human being is destroying our environment at a fast rate. For industrialization deforestation is going on large scale and this is a serious problem for us. It results in shortage of oxygen, excess of carbon dioxide which is increasing the temperature of planet leading to various natural calamities. Not only has this, polluting air, water and land which are giving birthed too many diseases. Along with this, creating noise pollution which creates deafness in people. Overall environment is getting disturbed. Who is responsible for this? It is not only the responsibility of the government to save the environment but it is the individual responsibility to solve the problem. Entrepreneur must understand that what kind of organization they are going to establish and what kind of products or services they are going to offer to their consumer. There is a famous saying is that "nature gives us more than it takes". So for industrial management, without giving respect to nature there is no question of increasing productivity, consumer satisfaction and profitability.

\section{CONCLUSION}

Industrial management has a very positive impact on consumers and environment. On the basis of analysis I would like to conclude that industrial management is not possible by considering only one factor. In fact it is a combination of all factors which have a direct impact on the business as well as environment. There should proper planning regarding demand forecasting, plant location, plant layout, material, its inventory management, latest and advance technologies, machines, proper production planning and control, correct selection of production system, considering the concept of TQM, supply chain management and realizing the importance of environment. All activities should be properly organized so that all activities run smoothly. Proper staffing should be there means recruiting the experienced, knowledgeable and skilled employees and delegate them their responsibilities according to their expertise. Along with this there should be proper training and development programs for employees and provide them all tools and equipments for doing the job in a best way. There should be the concept of fringe benefits, rewards, performance appraisal etc. Proper direction and supervision should be given to employees. Proper control actions should be taken by comparing the actual performance with the set standards.

\section{RECOMMENDATIONS}

- Employees should be aware of the concept of industrial management.

- Proper selection of proper planning regarding demand forecasting, plant location, plant layout, material, its inventory management, latest and advance technologies, machines, proper production planning and control, correct selection of production system, considering the concept of TQM, supply chain management and realizing the importance of environment.

- Investment in the research and development.

- Different training methods should be provided to the employees according to the requirement of the job.

- There should be reward for the good performance.

- There should be the concept of afforestation and reforestation which would minimize green house effect and global warming.

\section{REFERENCE}

1. M.Mahajan - industrial management (Dhanpat Rai \& Co. (p) Ltd.

2. T.N.Chhabra- industrial management (Sun India Publications)

3. J.Sangal-industrial management (Shubham Publications)

4. Anubhuti Dwivedi and Prateek Gupta (Ardent Publications)

5. www.omicsonline.org

6. www.emealdinsight.com

7. www.journals.elsevier.com

8. www.sciencedirect.com

9. www.talent.com 
10. Benefits of training and development for individuals and teams, organizations and society. By Herman Aguinis and Kurt Kraiger

11. Global Journal of management and business research (impact of training and development on organizational performance) by Raja Abdul Ghafoor Khan, Furqan Ahmed Khan, Dr.Muhammad Aslam Khan

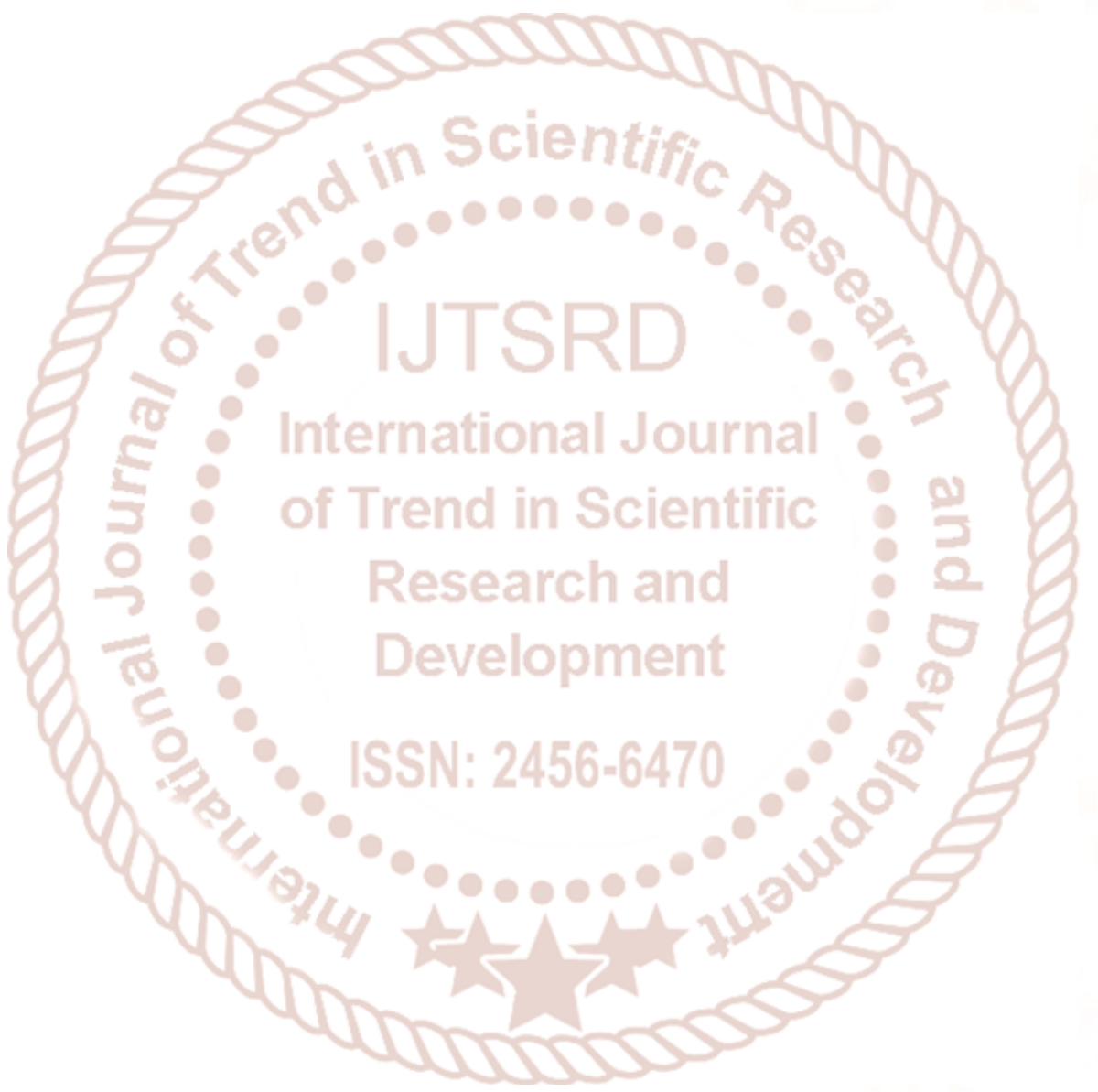

